\title{
Magnesium Deficiency in Patients on Long-term Diuretic Therapy for Heart Failure
}

\author{
PIN LIM, EDWARD JACOB
}

British Medical fournal, 1972, 3, 620-622

\begin{abstract}
Summary
Magnesium levels in serum, erythrocytes, skeletal muscle, and bone were measured in 10 patients with valvular heart disease who had received diuretic therapy for heart failure for an average of 3.3 years. Five patients were found to have diminished values for skeletal muscle, indicating significant magnesium deficit. Values for erythrocytes were low in only two of the five patients, and none had low values for serum ultrafiltrate and bone: Magnesium replacement therapy restored skeletal muscle values to normal. Clinical features consistent with the presence of magnesium deficiency were found in all five magnesium-deficient patients. These features were, with few exceptions, corrected by magnesium replacement. The latter also corrected low skeletal muscle potassium values present in all five patients with low skeletal muscle magnesium, four of whom showed clinical features of digoxin poisoning before magnesium therapy was given. Concomitant secondary aldosteronism, inadequate dietary intake, and digoxin therapy had probably augmented the magnesium loss due to diuretic therapy.
\end{abstract}

\section{Introduction}

Administration of diuretics may lead to significant urinary loss of magnesium (Martin et al., 1952; Barker et al., 1959; Smith et al., 1959; Wacker, 1961; Demartini et al., 1967; Parfitt, 1969). Patients with chronic valvular heart disease are often given long-term diuretic therapy for heart failure. The latter is itself associated with aldosteronism (Singer and Wener, 1953; Wolff et al., 1957), which could augment the urinary excretion of magnesium (Horton and Biglieri, 1962). It was therefore thought to be of interest to assess the magnesium status of patients receiving long-term diuretic therapy for heart failure in view of the clinical importance of magnesium deficiency, particularly with regard to digoxin toxicity and cardiac arrhythmias (Wacker, 1961; Demartini et al., 1967). In this study magnesium status was assessed on the basis of the concentration of magnesium in all accessible tissues; they included skeletal muscle and bone, which together contain over $80 \%$ of the total body magnesium (Widdowson and Dickerson, 1964).

\section{Materials and Methods}

Ten patients who had been admitted to hospital in congestive heart failure due to chronic valvular disease were studied. They had all been taking one or more diuretic drugs without break in the preceding six months at least, and had no history of having taken magnesium-containing drugs-for example,

\footnotetext{
Department of Medicine, Medical Unit 2, University of Singapore, Singapore 3

PIN LIM, M.D., M.R.C.P., Senior Lecturer Department of Biochemistry, the General Hospital, Sepoy Lines,
Singapore 3

EDWARD JACOB, PH.D., M.C.B., Biochemist
}

antacids-during the previous 12 months or more. There were no concomitant conditions likely to have caused magnesium loss, such as alcoholism, chronic vomiting, or diarrhoea.

The subjects were studied when they were not in overt heart failure and were clinically stable. Clinical features known to be associated with magnesium deficiency and those of digoxin toxicity were looked for. Blood was drawn without venous stasis for the extimation of serum magnesium (total and ultrafiltrable), erythrocyte magnesium, and serum calcium (total and ionized), sodium, potassium, and creatinine.

Biopsy of skeletal muscle and bone was carried out within a day of clinical examination. Specimens of bone were taken from the iliac crest (Williams and Nicholson, 1963). The skin incision was extended over the tensor fasciae latae and a small specimen (about $0.5 \mathrm{~g}$ ) was taken from this muscle. The biopsy specimens were analysed for magnesium and, in the case of skeletal muscle, potassium. Magnesium deficiency was deemed to be present if the magnesium level in skeletal muscle or bone (or both) was below the range found in specimens of normal tissues (see below).

Magnesium replacement was started as soon as magnesium deficiency was established provided that there was no clinical or biochemical evidence of renal insufficiency. Such patients were treated initially as inpatients for about two weeks, each receiving an infusion of $84 \mathrm{mEq}$ of magnesium sulphate (with 1 litre of $5 \%$ dextrose) over six hours every other day. They were assessed clinically just before the start of replacement therapy and daily while receiving infusions. Two patients were taken off diuretics and they continued to receive intravenous magnesium replacement therapy until their magnesium deficit had been made good, as indicated by the excretion of more than $90 \%$ of the infused magnesium in the urine within 48 hours of starting the infusion (Fourman and Morgan, 1962). After receiving their initial infusions three other subjects continued replacement therapy as outpatients, and during this period they were assessed clinically only once a week. During outpatient treatment they were each given $15 \mathrm{ml}$ of magnesium hydroxide mixture by mouth twice a day (equivalent to $96 \mathrm{mEq}$ magnesium/ day) and magnesium replacement was arbitrarily assumed to have been achieved after a total of six weeks' treatment. Serum magnesium, calcium, sodium, and potassium and erythrocyte magnesium were estimated every fourth day on inpatients but only once a week during outpatient follow-up.

Serum total magnesium was estimated with the atomic absorption spectrophotometer as described previously (Lim et al., 1969a). Serum calcium was similarly estimated (with wavelength set at $4,227 \AA$ ). In the estimation of serum ultrafiltrable magnesium the method of preparing serum ultrafiltrate previously described ( $\operatorname{Lim}$ et al., 1969b) was used. An aliquot of the ultrafiltrate prepared was used for the determination of ionized calcium spectrophotometrically (Unicam SP 600) by means of the $\mathrm{pH}$-independent compleximetric indicator tetramethylmurexide (Nordin and Smith, 1965).

Skeletal muscle and erythrocyte magnesium were estimated as previously described ( $\operatorname{Lim}$ et al., 1969a). Skeletal muscle potassium was measured on an aliquot of the skeletal muscle powder prepared as for magnesium estimation. The residue after incineration was dissolved in $0.1 \mathrm{~N}$ hydrochloric acid and the potassium content estimated with the E.E.L. flame photometer. Bone magnesium was estimated in the same way as skeletal muscle magnesium. Specimens of skeletal muscle for the estimation of normal magnesium and potassium values were 
obtained during surgical operations from consenting patients who were free of metabolic disorders-for example, during herniorrhaphy and orthopaedic operations (Lim et al., 1969a). Specimens of bone for estimation of normal magnesium values were obtained at necropsy from victims of road traffic accidents with no evidence of concomitant disease.

Serum and urine sodium and potassium were estimated with the E.E.L. flame photometer, and serum and urine creatinine by the method of Bonsnes and Taussky (1945).

\section{Results}

The duration of diuretic therapy varied from seven months to nine years (mean 3.3 years). All patients had received chlorothiazide, and frusemide and mersalyl had also been administered in some cases (Table I). There was evidence of cardiac cirrhosis in Cases 1, 7, and 8. All patients except Case 6 had either a poor diet or a poor appetite, ingesting not more than $30 \mathrm{~g}$ of protein daily. All patients were receiving maintenance doses of digoxin and potassium supplements.

Skeletal Muscle Magnesium.-Of the 10 subjects studied three (Cases 2, 5, and 8) had skeletal muscle magnesium values well below normal and two (Cases 1 and 10) had values just below the normal range (Table I). The mean for all 10 patients was significantly lower $(P<0.01)$ than that for normal controls (Table II). After magnesium replacement therapy in Cases 1, 2, and 5 skeletal muscle biopsy was repeated and gave normal magnesium values (Table I). There appeared to be no correlation between the duration of diuretic therapy and the severity of magnesium depletion as indicated by the skeletal muscle magnesium level.

Bone Magnesium.-All the patients, including those with reduced skeletal muscle magnesium levels, had normal bone magnesium levels. The mean value for the five patients with low skeletal muscle magnesium was not significantly different from that for normal controls (Table II).

Clinical Features.-Nausea and vomiting or ventricular ectopic beats, or both, the common manifestations of digoxin toxicity, were present in Cases 1, 2, 5, 7, and 10, in four of which there was evidence of magnesium deficiency (Table III). These features were promptly relieved after one magnesium infusion except in the patient who was not magnesium-deficient (Case 7). This patient, who was normokalaemic, was given a trial course of magnesium infusions, but her symptoms persisted for three days. Digoxin was withdrawn from all five patients immediately after the appearance of features of toxicity. Clinical features consistent with the presence of magnesium deficiency were seen in all five magnesium-deficient patients. The commonest were muscle cramps, exaggerated tendon reflexes, and paraesthesiae, and these were noticeably relieved in the course of magnesium therapy (Table III). Some of these clinical features were also present in Cases 7 and 9, but they were not relieved by the magnesium infusion in Case 7.

Serum Magnesium.-Of the five patients with low skeletal muscle magnesium two (Cases 1 and 8 ) had low serum total magnesium ( 1.60 and $1.62 \mathrm{mg} / 100 \mathrm{ml}$ respectively), while all those with normal skeletal muscle magnesium had normal serum total magnesium. The mean value for the five magnesiumdeficient patients was significantly lower $(P<0.001)$ than that for normal controls (Table II). Magnesium replacement in the five deficient patients, however, did not result in any significant change in their mean value. In all 10 patients, including the two with hypomagnesaemia, the serum untrafiltrable magnesium values were within the normal range. Magnesium replacement did not significantly change the mean value for the deficient patients. Low serum albumin levels due to liver cirrhosis in Cases 1 and $8(2.8$ and $2.5 \mathrm{~g} / 100 \mathrm{ml}$ respectively) would account for their low serum total magnesium values.

Erythrocyte Magnesium.-Two (Cases 2 and 8) of the five

TABLE I-Clinical and Biochemical Data on 10 Patients on Prolonged Diuretic Therapy for Heart Failure

\begin{tabular}{|c|c|c|c|c|c|c|c|c|c|c|}
\hline Case No.: & $1^{*}$ & 2* & 3 & 4 & $5^{*}$ & 6 & 7 & $8^{*}$ & 9 & $10^{*}$ \\
\hline $\begin{array}{l}\text { Sex and age .. } \\
\text { Duration (years) of chlorothiazide therapy } \\
\text { Supplementary diuretics (frusemide or mersalyl) } \ldots \\
\text { Clinical features suggesting digoxin toxicity } \\
\text { Skeletal muscle magnesium (mEq/kg dry fat-free } \\
\text { solids; normal range } 59 \cdot 4-82 \cdot 2) \\
\text { Skeletal muscle potassium (mEq/kg dry fat-free } \\
\text { solids; normal range } 294-386)\end{array}$ & $\begin{array}{c}\text { F. } 65 \\
9 \\
+ \\
+ \\
58 \cdot 8(67) \dagger \\
250(320) \dagger\end{array}$ & $\begin{array}{c}\text { F. } 35 \\
3 \\
+ \\
+ \\
48 \cdot 8(71 \cdot 5) \\
218(341)\end{array}$ & $\begin{array}{l}\text { M. } 34 \\
- \\
- \\
61 \cdot 3\end{array}$ & $\begin{array}{l}\text { M. } 51 \\
\text { months } \\
+ \\
- \\
67 \cdot 3 \\
370\end{array}$ & $\begin{array}{c}\text { F. } 47 \\
4 \\
+ \\
+ \\
53 \cdot 1(64 \cdot 2)\end{array}$ & $\begin{array}{l}\text { M. } 27 \\
\frac{-}{62 \cdot 4}\end{array}$ & $\begin{array}{c}\text { F. } 39 \\
\frac{21}{2} \\
+ \\
61.5\end{array}$ & $\begin{array}{c}\text { M. } 56 \\
\frac{2}{-} \\
- \\
50.7\end{array}$ & $\begin{array}{c}\text { M. } 55 \\
31 \\
= \\
59.5\end{array}$ & $\begin{array}{l}M_{3 \frac{1}{2}} 34 \\
+ \\
+ \\
58 \cdot 5 \\
254\end{array}$ \\
\hline
\end{tabular}

*Patient magnesium-deficient.

+Values in parentheses are those obtained after magnesium replacement therapy.

TABLE II-Analysis of Biochemical Data (Mean \pm S.D.) on Normal Controls and Patients on Prolonged Diuretic Therapy for Heart Failure

\begin{tabular}{|c|c|c|c|c|c|c|}
\hline & $\begin{array}{c}\text { Muscle Magnesium } \\
\text { (mEq/kg Dry Fat- } \\
\text { free Solids) }\end{array}$ & $\begin{array}{l}\text { Bone Magnesium } \\
\text { (mEq/kg Dry Fat- } \\
\text { free Solids) }\end{array}$ & $\begin{array}{c}\text { Serum } \\
\text { Total Magnesium } \\
(\mathrm{mg} / 100 \mathrm{ml})\end{array}$ & $\begin{array}{l}\text { Serum Ultrafiltrable } \\
\text { Magnesium (mg/ } \\
100 \text { ml Ultrafiltrate) }\end{array}$ & $\begin{array}{l}\text { Erythrocyte } \\
\text { Magnesium (mg/ } \\
100 \mathrm{ml} \text { Cells) }\end{array}$ & $\begin{array}{c}\text { Muscle Potassium } \\
\text { (mEq/kg Dry Fat- } \\
\text { free Solids) }\end{array}$ \\
\hline $\begin{array}{l}\text { A, Normal controls (No. of subjects) } \\
\text { B, Magnesium-deficient patients }(\mathbf{n}=\mathbf{5}) \\
\text { C. All patients studied }(\mathbf{n}=10) \\
\text { Difference }\left\{\begin{array}{lllll}\text { AB } & \ldots & \ldots & \ldots & \ldots \\
\text { AC } & \ldots & \ldots & \ldots & \ldots\end{array}\right.\end{array}$ & $\begin{array}{l}70 \cdot 8 \pm 5 \cdot 7(30) \\
54 \cdot \frac{2}{2} \pm 4 \cdot 3 \\
58 \cdot 3 \pm 5 \cdot 5 \\
P<0 \cdot 001 \\
P<0 \cdot 01\end{array}$ & $\begin{array}{c}212 \cdot 6 \pm 23 \cdot 1(47) \\
205 \cdot \frac{ \pm}{4} \pm 17 \cdot 7 \\
200 \cdot 6 \pm 16 \cdot 2 \\
\text { N.S. } \\
\text { N.S. }\end{array}$ & $\begin{array}{c}2.0 \pm 0.17(87) \\
1.68 \pm 0.08 \\
1.77 \pm 0.13 \\
P<0.001 \\
P<0.01\end{array}$ & $\begin{array}{c}1.69 \pm 0.17(25) \\
1.40 \pm 0.01 \\
1.50 \pm 0.11 \\
\mathbf{P}<0.001 \\
\mathbf{P}<0.01\end{array}$ & $\begin{array}{c}6.26 \pm 0.88(56) \\
4.44 \pm 0.51 \\
4.57 \pm 0.45 \\
P<0.001 \\
P<0.001\end{array}$ & $\begin{array}{c}340 \cdot 2 \pm 23.0(30) \\
259 \cdot \frac{1}{2} \pm 29 \cdot 2 \\
316.6 \pm 66 \cdot 2 \\
P<0.001 \\
P<0.01\end{array}$ \\
\hline
\end{tabular}

N.S. $=$ Not significant.

TABLE III-Clinical Features present before Replacement Therapy*

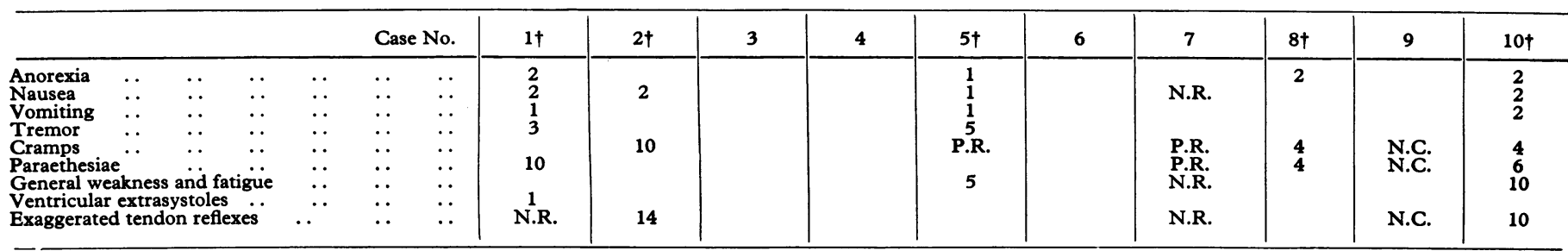

* Figures indicate number of days from start of replacement therapy when symptom or sign disappeared. Blank space denotes absence of symptom or sign.

†.Patient magnesium-deficient.

P.R. = Partial response at conclusion of magnesium therapy (frequency of cramps reduced). 
patients with low skeletal muscle magnesium had low erythrocyte magnesium values $(3.68$ and $4.20 \mathrm{mg} / 100 \mathrm{ml}$ cells respectively). The mean value for the five patients was significantly lower $(P<0.001)$ than that for the normal controls (Table II). With magnesium therapy the low values rose.

Calcium.-All 10 patients were normocalcaemic, and the level of ionized calcium, the biologically important moiety of serum calcium, was just below the lower limit of normal in only one patient (Case 2).

Potassium.-Only one of the 10 patients (Case 1) had hypokalaemia, which was mild and was corrected with magnesium repletion alone. Skeletal muscle potassium, however, was noticeably reduced in all the magnesium-deficient patients (Table I). There was a statistically significant difference ( $P<0.001$ ) between the mean for the magnesium-deficient patients and that for normal controls (Table II). Magnesium replacement brought the values back to normal in all three patients in whom it was possible to repeat muscle biopsy (Table I).

\section{Discussion}

The prevalence of magnesium deficiency, as shown by low skeletal muscle magnesium, among patients with heart failure on long-term diuretic therapy seems to be of the order of $50 \%$. There appears to have been no previous investigation into the frequency and severity of magnesium deficiency in similar circumstances, although the clinical importance of such a deficiency has been emphasized (Wacker, 1961; Seller et al., 1966; Wacker and Parisi, 1968).

Skeletal muscle magnesium accounts for about $20 \%$ of the total body magnesium (Widdowson and Dickerson, 1964) and is a reliable index of total body magnesium (MacIntyre and Davidsson, 1958; MacIntyre et al., 1958). Moreover, if the magnesium status of this tissue accurately reflects that of metabolically active cells in general, the skeletal muscle magnesium level is a logical index of clinical magnesium status, since magnesium in intimately involved in a wide range of cellular enzyme reactions. Bone, erythrocyte, and serum magnesium levels, in contrast, appear to be unreliable in the diagnosis of magnesium deficiency.

In the present series of cases intracellular potassium was invariably low when intracellular magnesium was low, and replacement with magnesium alone led to the restoration to normal of the intracellular levels of both cations. Each of the patients received a constant potassium supplement of $40 \mathrm{mEq} /$ day before and throughout the study. The intimate relation between intracellular potassium and magnesium found in experimental work on rats (Whang and Welt, 1963) is thus confirmed in man. The high incidence of digoxin toxicity among magnesium-deficient patients (four out of five) is worth noting. The effect of magnesium replacement is difficult to assess as digoxin was withdrawn once toxicity was suspected. Potassium deficiency has long been known to predispose to digoxin toxicity. It is not clear, however, whether the increased liability to digoxin toxicity in these deficient patients is related to magnesium deficiency per se or to concomitant secondary intracellular potassium depletion. In any case, magnesium supplements alone would correct both abnormalities and might be expected to reduce the liability to digoxin toxicity.

All the patients were in a stable clinical state when they were studied. Practically all the clinical features suggestive of magnesium deficiency in the five deficient patients were abolished by magnesium replacement therapy. In Cases 7 and 9, however, there was no biochemical evidence of magnesium deficiency although their clinical resemblance to the five deficient patients was noticeable. These two subjects serve as a useful reminder that clinical features alone can be misleading.

In view of the well-documented magnesuric property of diuretics (Martin et al., 1952; Barker et al., 1959; Smith et al., 1959; Wacker, 1961; Demartini et al., 1967; Parfitt, 1969) the present patients, who had been taking diuretics on average for 3.3 years, had probably lost quite large quantities of magnesium in the urine. One of the major factors in magnesium conservation is reduction of urinary magnesium excretion, so that if excretion is not stimulated by diuretics the obligatory urinary loss may be reduced to less than $1 \mathrm{mEq} /$ day when dietary magnesium is severely restricted (Barnes et al., 1958). All the magnesium-deficient patients had a poor dietary intake, and with the impaired alimentary absorption expected in heart failure and the persistent renal magnesium loss the presence of magnesium deficiency is not surprising.

It may be relevant that intracellular magnesium depletion is known to occur in patients with protein calorie malnutrition (Montgomery, 1960). Excessive secretion of aldosterone in patients with cardiac oedema is well established (Singer and Wener, 1953; Wolff et al., 1957), and aldosterone augments the urinary excretion of magnesium (Horton and Biglieri, 1962). Furthermore, digoxin inhibits renal tubular transport of magnesium (Kupfer and Kosovsky, 1965). It would be interesting to define the relative contributions of hyperaldosteronism, digoxin therapy, inadequate dietary intake, and diuretic therapy to the state of magnesium deficiency met with in patients such as these.

\section{References}

Barker, E. S., Elkinton, J. R., and Clark, J. K. (1959). Journal of Clinical Investigation, 38, 1733.

Barnes, B. A., Cope, O., and Harrison, T. (1958). fournal of Clinical Investigation, 37,430 .

Bonsnes, R. W., and Taussky, H. H. (1945). fournal of Biological Chemistry, 158,581 .

Demartini, F. E., Briscoe, A. M., and Ragan, C. (1967). Proceedings of the Society for Experimental Biology and Medicine, 124, 320.

Fourman, P., and Morgan, D. B. (1962). Proceedings of the Nutrition Society, 21,34 .

21, 34.
Horton, R., and Biglieri, E. G. (1962). Fournal of Clinical Endocrinology and Metabolism, 22, 1187 .

Kupfer, S., and Kosovsky, J. D. (1965). Journal of Clinical Investigation, 44, 1132.

Lim, P., Jacob, E., Dong, S., and Khoo, O. T. (1969a). fournal of Clinical Pathology, 22, 417.

Lim, P., Jacob, E., and Khoo, O. T. (1969b). Medical fournal of Australia, 1,1172 .

MacIntyre, I., and Davidsson, D. (1958). Biochemical fournal, 70, 456.

MacIntyre, I., Davidsson, D., and Leong, P. C. (1958). In Abstracts of IV International Congress Biochemistry, Vienna, p. 160. Oxford, Pergamon. Martin, H. E., Mehl, J., and Wertman, M. (1952). Medical Clinics of North America, 36, 1157.

Montgomery, R. D. (1960). Lancet, 2, 74

Nordin, B. E. C., and Smith, D. A. (1965). Disorders of Calcium Metabolism,

p. 163. London, Churchill. A. (196). Clinical Science, 36, 267.

Peller, R. H., Ramirez, O., Brest, A. N., and Moyer, J. H. (1966). American fournal of Cardiology, $17,786$.
for

Singer, B., and Wener, J. (1953). American Heart fournal, 45, 795.

Smith, W. O., Kyriakopoulos, A., Mock, D. C., and Hammarsten, J. F. (1959). Clinical Research, 7, 162 .

Wacker, W. E. C. (1961). Fournal of Clinical Investigation, 40, 1086.

Wacker, W. E. C., and Parisi, A. F. (1968). New England fournal of Medicine, 278, 772 .

Whang, R., and Welt, L. G. (1963). Fournal of Clinical Investigation, 42, 305.

Widdowson, E. M., and Dickerson, J. W. T. (1964). Mineral Metabolism, ed. C. L. Comar and F. Bronner, vol. 2, part A, p. 2. New York, Academic Press.

Williams, J. A., and Nicholson, G. I. (1963). Lancet, 1, 1408.

Wolff, H. P., Koczorek, K. R., and Buchborn, E. (1957). Lancet, 2, 63. 